\title{
Upaya menurunkan morbiditas dan mortalitas ibu hamil melalui penyuluhan dan skrining risiko kehamilan di Kelurahan Tuan Kentang Palembang
}

\author{
Rista Silvana*, Ratih Pratiwi, Ary Rinaldzi \\ Fakultas Kedokteran, Universitas Muhammadiyah Palembang, Indonesia \\ E-mail : dr.ristasilvana.spog@gmail.com
}

\begin{abstract}
Abstrak
Angka kematian ibu di Sumatera Selatan masih tinggi. Morbiditas dan mortalitas ibu dapat dihindari dengan melakukan kunjungan layanan antenatal (ANC) secara teratur. Meskipun cakupan ANC di Indonesia semakin meningkat, namun angka di Sumatera Selatan masih di bawah rata-rata nasional. Perlu dilakukan edukasi untuk meningkatkan pengetahuan ibu agar rutin memeriksakan kehamilan. Tujuan dilakukan pengabdian masyarakat di Kelurahan Tuan Kentang adalah untuk memberikan penyuluhan akan pentingnya ANC dan skrining risiko kehamilan untuk mengurangi morbiditas dan mortalitas ibu. Sebanyak 20 orang ibu hamil berpartisipasi pada kegiatan ini. Hanya sembilan orang (45\%) yang melakukan ANC dengan jumlah yang cukup. Rendahnya tingkat pendidikan, kurangnya pengetahuan tentang ANC, dan jarak tempuh ke layanan kesehatan merupakan faktor yang menghambat ibu melakukan ANC. Sebanyak 17 orang (85\%) memiliki kehamilan risiko ringgi karena terkait usia, paritas, riwayat kehamilan sebelumnya, kelainan letak janin, penyakit ibu terkait kehamilan maupun infeksi, dan gangguang ginekologis. Sebagian besar peserta kurang melakukan kujnungan $\mathrm{ANC}$, dan berada pada kategori risiko kehamilan tinggi.
\end{abstract}

Kata kunci: Morbiditas Ibu, Mortalitas Ibu, Kehamilan, Layanan Antenatal, Risiko Kehamilan

\begin{abstract}
Efforts to reduce maternal morbidity and mortality through counseling and pregnancy risk screening in at Kelurahan Tuan Kentang Palembang. The maternal mortality rate in South Sumatra is still high. Maternal morbidity and mortality can be avoided by having regular antenatal care (ANC) visits. Although the coverage of ANC in Indonesia is increasing, the number in South Sumatra is still below the national average. Education is needed to increase the knowledge of mothers so that they routinely have pregnancy visits. The aim of the community service in Tuan Kentang Village are to improve knowledge of the importance of ANC and provide pregnancy risk screening to reduce maternal morbidity and mortality. A total of 20 pregnant women participated in this activity. Only nine people (45\%) performed ANC in sufficient numbers. Low level of education, lack of knowledge about ANC, and distance to health services are factors that prevent mothers from doing ANC. As many as 17 people (85\%) had high risk pregnancies due to age, parity, previous pregnancy history, fetal abnormalities, maternal diseases related to pregnancy or infection, and gynecological disorders. Most of the participants did less ANC visits, and were in the high pregnancy risk category.
\end{abstract}

Keywords: Maternal Morbidity, Maternal Mortality, Pregnancy, Antenatal Care, Pregnancy Risk 


\section{PENDAHULUAN}

Pembangunan kesehatan masih dihadapkan pada permasalahan kesehatan yang belum terselesaikan seperti penurunan angka kematian ibu dan kematian janin, penurunan angka kekurangan gizi, penurunan total fertility rate (TFR), penanggulangan penyakit menular dan tidak menular, peningkatan upaya promotif dan preventif, dan peningkatan akses terhadap pelayanan kesehatan. Indikator peningkatan kesehatan masyarakat menurut kementerian kesehatan salah satunya adalah menurunkan angka kematian ibu dari 359 per 100.000 kelahiran hidup menjadi 306 per 100.000 kelahiran hidup. Angka kematian ibu di Provinsi Sumatera Selatan pada tahun 2018 sebesar 199 orang, dengan penyebab terbanyak adalah pendarahan dan hipertensi. Angka ini mengalami peningkatan dari tahun sebelumnya yang berjumlah 107 orang. ${ }^{1}$

Terdapat kasus kematian delapan belas neonatus dan enam bayi (usia 29 hari-11 bulan) di tahun 2018 dari 26.837 kelahiran hidup di Sumatera Selatan. Berat badan lahir rendah (BBLR), asfiksia, kelainan bawaan, adalah beberapa diantara penyebab kematian tersebut. ${ }^{1}$ Untuk mencegah terjadinya kematian pada bayi, kesehatan ibu selama kehamilan harus dipantau dengan baik.

Kota Palembang terdiri dari enam belas kecamatan. Universitas Muhammadiyah Palembang terletak di Kecamatan Seberang Ulu I, sehingga kegiatan pengabdian masyarakat ini difokuskan pada masyarakat sekitar institusi. Edukasi dan layanan pemeriksaan kesehatan ini dilaksanakan di Kelurahan Tuan Kentang Kecamatan Seberang Ulu I, Palembang. Tujuan kegiatan ini adalah untuk meningkatkan pengetahuan pada ibu hamil tentang pemeriksaan rutin kehamilan dan mengetahui tingkat risiko kehamilannya.

\section{TINJAUAN PUSTAKA}

Angka kematian ibu masih tinggi di Indonesia, dengan pendarahan dan hipertensi menjadi penyebab terbanyak. Pada tahun 2018, tercatat angka kematian ibu sebesar 199 orang di 
Sumatera Selatan. ${ }^{1}$ Agar proses kehamilan dapat berjalan dengan baik, ibu harus rutin memeriksakan kehamilannya.

Akses ibu hamil terhadap layanan antenatal/ antenatal care (ANC), digambarkan melalui indikator cakupan kunjungan ibu hamil yang melakukan kontak sesuai standar dengan tenaga kesehatan berkompetensi. Kunjungan pertama (K1) dilakukan sedini mungkin pada trimester pertama, sebaiknya sebelum minggu ke 8. Kunjungan ke-4 (K4) adalah istilah yang menyatakan ibu hamil melakukan kontak 4 kali atau lebih dengan aturan minimal satu kali pada trimester I (0-12 minggu), minimal satu kali pada trimester II (>12-24 minggu), dan minimal 2 kali pada trimester III (>24 minggu sampai dengan kelahiran). ${ }^{2}$

Berdasarkan Riset Kesehatan Dasar (Riskesdas) tahun 2018, cakupan ANC di Indonesia mengalami peningkatan menjadi 96,1\%, dari sebelumnya 95,2\% di tahun 2013. Cakupan pemeriksaan K4 juga meningkat dari 70,0\% menjadi 74,1\%. Akan tetapi, cakupan ANC dan K4 di Sumatera Selatan masih berada di bawah rata-rata nasional. ${ }^{3}$

Pemeriksaan kehamilan yang rutin dapat membantu mengenali gejala kehamilan risiko tinggi, di antaranya ibu memiliki riwayat kehamilan sebelumnya yang kurang baik, tinggi badan kurang dari $145 \mathrm{~cm}$, kurang gizi, usia kurang dari 20 tahun atau lebih dari 35 tahun, memiliki $>3$ anak, jarak antar kehamilan yang terlalu berdekatan anemia $(\mathrm{Hb}<8$ gr \%), tekanan darah tinggi (>140/90 $\mathrm{mmHg}$ ), edema nyata, eklampsia, perdarahan pada kehamilan, ketuban pecah dini, kelainan letak janin, dan memiliki penyakit infeksi atau penyakit kronik. ${ }^{5,6}$

Pemeriksaan kelainan letak janin dan gangguan pada rahim dapat dideteksi dengan ultrasonografi (USG). World Health Organization (WHO) merekomendasikan pemeriksaan USG satu kali sebelum usia gestasi 24 minggu untuk memperkirakan usia gestasi, mendeteksi kelainan janin, jumlah janin, keadaan plasenta dan rahim, sehingga kesulitan persalinan nantinya dapat dihindari. ${ }^{6}$ 


\section{METODE}

Solusi yang dapat ditawarkan untuk menurunkan angka morbiditas dan mortalitas ibu hamil di Kelurahan Tuan Kentang yaitu melalui penyuluhan untuk meningkatkan kesadaran masyarakat dalam melakukan pemeriksaan antenatal rutin. Penyuluhan membahas tentang pengetahuan seputar kehamilan, pemeriksaan yang harus dilakukan saat hamil, kehamilan risiko tinggi, anjuran dan larangan dalam kehamilan, serta penatalaksanaan kehamilan sesuai indikasi medis. Terdapat sesi diskusi untuk memberikan kesempatan bertanya kepada peserta. Setelah itu, dilakukan pemeriksaan fisik kehamilan dan USG untuk mengetahui tingkat risiko kehamilan.

\section{HASIL DAN PEMBAHASAN}

Kegiatan berlangsung lancar dengan jumlah ibu hamil yang datang memeriksakan kehamilan sebanyak dua puluh orang. Data yang didapatkan menunjukkan bahwa pemeriksaan kehamilan rutin yang dilakukan oleh ibu hamil peserta kegiatan cukup rendah. Hanya 9 orang (45\%) yang rutin memeriksakan kehamilannya sesuai ketentuan minimal kunjungan.

Tabel 1. Karakteristik peserta kegiatan

\begin{tabular}{lcc}
\hline Karakteristik & $\mathrm{N}(20)$ & $\%$ \\
\hline Kunjungan ANC & & \\
$\quad$ Cukup & 9 & 45 \\
$\quad$ Kurang & 11 & 55 \\
Usia & & \\
$\quad<20$ tahun & 2 & 10 \\
$20-35$ tahun & 13 & 65 \\
$\quad>35$ tahun & 5 & 25 \\
Usia kehamilan & & \\
$\quad$ Trimester 1-2 & 9 & 45 \\
$\quad$ Trimester 3 & 11 & 55 \\
Risiko kehamilan & & \\
$\quad$ Tinggi & 17 & 85 \\
$\quad$ Rendah & 3 & 15 \\
\hline
\end{tabular}


Penelitian di Lampung pada tahun 2017 membagi faktor-faktor yang memengaruhi keputusan ibu melakukan ANC sebagai faktor predisposisi, pemungkin, dan penguat. ${ }^{7}$ Pada peserta kegiatan ini, faktor predisposisi berupa tingkat pendidikan dan pengetahuan, juga faktor pemungkin berupa jarak tempuh ke lokasi layanan kesehatan, menjadi penyebab kurangnya kunjungan ANC. Kurangnya pengetahuan ibu juga menjadi penyebab kurangnya kunjungan ANC pada penelitian lain di daerah lain berdasarkan penelitian sebelumnya. ${ }^{89}$

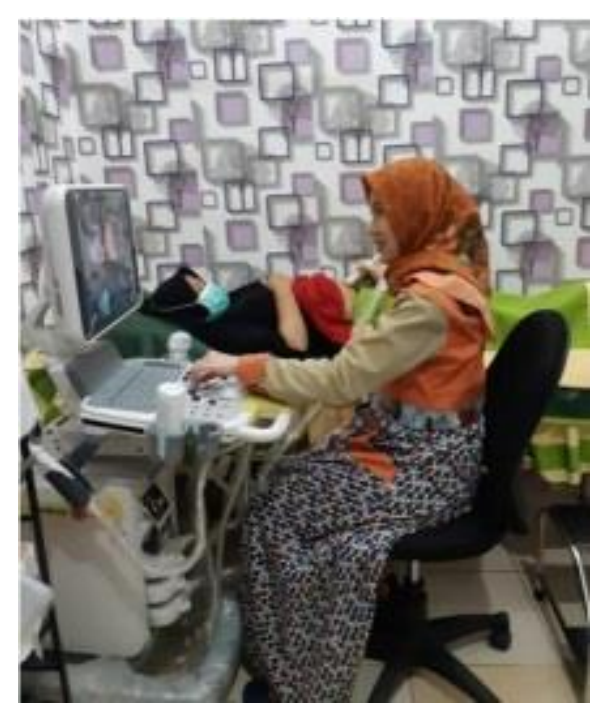

Gambar 1. Pemeriksaan USG pada ibu hamil

Hasil pemeriksaan menunjukkan sebagian besar peserta masuk dalam kategori kehamilan risiko tinggi. Tujuh peserta berada pada usia $<20$ tahun dan $>35$ tahun yang merupakan salah satu komponen yang meningkatkan risiko. ${ }^{5}$ Dua orang memiliki risiko karena paritas lebih dari tiga, dan tiga orang memiliki riwayat abortus sebelumnya. Pada penelitian sebelumnya, riwayat kehamilan dan paritas dinyatakan berhubungan dengan kejadian kehamilan risiko tinggi. ${ }^{5}$

Penyakit yang dialami peserta yang meningkatkan risiko diantaranya kehamilan dengan herpes genitalis, preeklampsia berat, presentasi bokong, asma bronkial, lilitan tali pusat, dan letak lintang. Selain diagnosis kehamilan juga ditemui diagnosis ginekologi, 
diantaranya abortus inkomplit, mola hidatidosa, death conceptus, missed abortion, kista endometriosis, mioma uteri. Diagnosis yang didapatkan sangat beragam dan mengarah ke risiko tinggi yang harus ditatalaksana lebih lanjut di rumah sakit.

Mortalitas ibu di Provinsi Sumatera Selatan paling banyak disebabkan oleh pendarahan dan hipertensi. ${ }^{1}$ Pada penelitian di RSUD Palembang Bari tahun 2010-2012, didapatkan bahwa kasus pendarahan pascapersalinan terbanyak disebabkan oleh sisa plasenta. ${ }^{10}$ Hipertensi merupakan faktor paling dominan yang menyebabkan preeklampsia pada penelitian di RSUP Dr. Mohammad Hoesin Palembang tahun 2016. ${ }^{11}$

Meskipun rekomendasi untuk melakukan pemeriksaan USG pada ibu hamil adalah sebelum 24 minggu, tidak semua peserta sudah mendapatkan layanan tersebut. Meskipun demikian, pemeriksaan USG pada trimester akhir masih tetap dibutuhkan bila belum pernah dilakukan sebelumnya, dengan tujuan mengidentifikasi jumlah janin, presentasi bayi, dan keadaan plasenta. Hasil pemeriksaan tersebut dapat membantu keputusan diagnosis dan tatalaksana selanjutnya. ${ }^{6}$

Melakukan kunjungan antenatal secara teratur sangat penting bagi ibu hamil. Pengabdian masyarakat ini sangat bermanfaat untuk memberikan pengetahuan kepada peserta mengenai pentingnya pemeriksaan kehamilan, sekaligus mendeteksi kelainan kehamilan melalui USG. Deteksi risiko kehamilan secara dini dapat mempercepat tatalaksana, sehingga menurunkan risiko morbiditas dan mortalitas ibu dan bayi.

\section{SIMPULAN}

Angka pemeriksaan kehamilan dan pemeriksaan USG di Kelurahan Tuan Kentang masih rendah dan masih banyak ditemukan kehamilan risiko tinggi yang tidak terdeteksi sebelumnya. Ibu disarankan untuk melapor ke Pusat Kesehatan Masyarakat (Puskesmas) di wilayahnya untuk mendapatkan rujukan ke pelayanan yang lebih tinggi. Selanjutnya, disarankan kepada Puskesmas utama maupun pembantu di wilayah Kelurahan Tuan Kentang untuk membuat program optimalisasi kunjungan ibu hamil. 


\section{Ucapan Terima Kasih}

Terima kasih kepada Rektor dan Dekan Fakultas Universitas Muhammadiyah Palembang yang telah memfasilitasi terlaksananya kegiatan pengabdian masyarakat ini melalui pembiayaan Hibah Internal Universitas Muhammadiyah Palembang.

\section{Referensi}

1. Dinas Kesehatan Provinsi Sumatera Selatan. Rencana kinerja tahunan dekonsentralisasi Dinas Kesehatan tahun 2019 [Internet]. 2019 [cited 2019 Sep 12].

2. Peraturan Menteri Kesehatan Republik Indonesia nomor 97 tahun 2014 tentang pelayanan kesehatan masa sebelum hamil, masa hamil, persalinan, dan masa sesudah melahirkan, penyelenggaraan pelayanan kontrasepsi, serta pelayanan kesehatan seksual. Kementerian Kesehatan RI; 2014 p. 1-119.

3. Hasil utama Riskesdas 2018 [Internet]. Badan Penelitian dan Pengembangan Kesehatan Kementerian Kesehatan RI; 2018 [cited 2019 Sep 10].

4. Marniyati L, Saleh I, Soebyakto BB. Pelayanan antenatal berkualitas dalam meningkatkan deteksi risiko tinggi pada ibu hamil oleh tenaga kesehatan di Puskesmas Sako, Sosial, Sei Baung dan Sei Selincah di Kota Palembang. Januari. 2016;3(1): 355-62.

5. Nursal DGA, Satri RM. Kehamilan risiko tinggi di Puskesmas Lubuk Gadang Kabupaten Solok Selatan. J Kesehat Masy Andalas. 2015;9(1): 23-8.

6. Organization WH. WHO recommendations on antenatal care for a positive pregnancy experience [Internet]. 2016 [cited 2019 Sep 13].

7. Rachmawati AI, Dewi Puspitasari R, Cania E. Faktor-faktor yang memengaruhi kunjungan antenatal care (ANC) ibu hamil. J Major. 2017;7(1): 72-6.

8. Fitrayeni F, Suryati S, Faranti RM. Penyebab rendahnya kelengkapan kunjungan antenatal care ibu hamil di wilayah kerja Puskesmas Pegambiran. J Kesehat Masy Andalas. 2017;10(1): 101-7.

9. Tinamonga Z, Kolibu FK, Ratag BT. Faktor-faktor yang berhubungan dengan pemanfaatan pelayanan antenatal care di wilayah kerja Puskesmas Sawang Kabupaten Siau Tagulandang Biaro. J KESMAS. 2018;7(5).

10. Daud S, Fitriani N. Karakteristik dan penyebab hemorrhagic post partum yang dialami oleh ibu di RSUD Palembang Bari periode 2010-2012. Syifa' Med J Kedokt dan Kesehat. 2015;5(2): 73-81.

11. Gustri Y, Sitorus RJ, Utama F. Determinan kejadian preeklampsia pada ibu hamil di RSUP Dr. Mohammad Hoesin Palembang. J Ilmu Kesehat Masy. 2016;7(3): 209-17. 